\title{
An Exploratory Study on Development of Effective Strategies in Social Media
}

\author{
Ong Sing Ling*a, Jill Ling Pei Wah ${ }^{\mathrm{b}}$

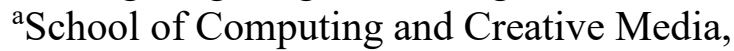 \\ ${ }^{\mathrm{b}} \mathrm{School}$ of Foundation Studies, \\ University College of Technology Sarawak, \\ Sibu, Malaysia \\ *Corresponding Author: eileenong@ucts.edu.my
}

\begin{abstract}
With the development of mobile computing, the focus of the marketing media has shifted from traditional media to social media. We are no longer solely reliant on the newspapers, radio and television for marketing. In fact, people are inclined to go online on social media every day. One of the popular social media today is WeChat. As a mobile app, WeChat has been widely used for social networking and business purposes. This research serves as a groundwork to explore and study on the strategies in using WeChat as a self-branding marketing tool, which leads to enhanced relationships and increased sales. To conduct this research, qualitative method which involved interviews and observations were used to gather the data. Thirty interviews were conducted to elicit the ideas or beliefs from WeChat users who are micro e-marketers. Observations in WeChat groups and WeChat Moments were carried out. All the data collection was subsequently analysed using content analysis. Results indicated that effective WeChat marketing strategies are composed of four main aspects: WeChat followers strategy, WeChat self-branding strategy, WeChat Moments strategy and WeChat groups marketing strategy. This exploratory study contributes a fundamental knowledge about effective WeChat marketing strategies. The research results provided insights into how WeChat can be used as a platform to establish, keep and satisfy the customers; create job opportunities for society and overall, bring welfare to the nation.
\end{abstract}

Keywords: WeChat, marketing, Social networking, Micro e-marketer, Qualitative

\section{Introduction}

Today, in the mobile Internet era, we are addicted to smartphones and Internet. This phenomenon has prompted many people to start venturing into online businesses as micro e-marketers in line with the digital economy. Micro e-marketers (or Wei Shang in Chinese) are individuals who sell their products or services over the Internet. In fact, Internet-based businesses have existed for ages as the platform for buyers and sellers to meet up. It places leverage information technology to match buyers and sellers with increased effectiveness and lower transaction costs. Marketers are fortunate to have a vast number of free and low-cost online services to provide insights on the customers that fuel marketing by delivering automated, real-time communications integrated across desktop, mobile and digital plus traditional marketing channels (Chaffey, 2016). 
According to Jack Ma, a famous Chinese business magnate in successful Internet-based businesses, the best business in the world is being the micro e-marketers where sales can be closed anytime anywhere regardless of work or play. Jack Ma never expected how quickly Tencent's WeChat would challenge Taobao marketplace operated by Alibaba Group (Yang, 2016). Despite the usefulness of WeChat as another social network marketing tool, little is known about WeChat marketing.

The objectives of this study were to explore the possible functions of WeChat and the strategies used by the micro e-marketers to satisfy the customers' needs while optimising profit. The research questions were specified as follows:

\section{Research Questions}

- What are the effective strategies in using WeChat in marketing?

- What are the best time strategies for being active in WeChat?

It is believed that such a study will be a significant precursor to further determine effective WeChat marketing strategies.

\section{Methodology}

Personal interviews and observations on WeChat Moments were carried out to collect the data for this study. Thirty respondents who are micro e-marketers were predetermined for interviews, a useful qualitative approach in assimilating in-depth information. Before the actual interviews, a pilot study was carried out with three persons to check whether interview questions were clear for respondents to answer.

Funnel approach was adopted, beginning with broad questions, such as 'Could you tell me your life story as a successful micro e-marketer?' and 'What comes to mind when you want to post in WeChat Moments?' and ending with specific questions, such as 'What is the best time to post in WeChat Moments?' in behavioral and time strategies (Hair et al., 2006). The interviews took place from November 2017 to August 2018, conducted at the respondents' convenient meet-up places, including respondents' homes or quiet cafés and even via online Skype to ensure their convenience. All interviews were audio-recorded for qualitative content analysis and subsequently transcribed into interview texts. Analysis of the raw data from verbatim transcribed interviews was used to form categories or themes.

\section{Literature Review}

WeChat (Wei Xin in Chinese) is a mobile application (instant messaging, commerce and payment services) that emerged in 2011 by Tencent Holdings. By 2015, the platform boasted some 600 million daily-active users (Bao, 2015). By 2017, it was one of the largest standalone messaging apps by monthly active users, with over 963 million monthly active users (Frater, 2017). Prior to the WeChat Pay launch in Malaysia, a senior VP of Tencent claimed that there were 20 million active WeChat users in Malaysia as of late 2017 (Rachel, 2018). WeChat provides a platform for such online businesses to be made possible where people have more time to enjoy their lives through the concept of working from home.

Nowadays, with the invention of smartphones, we are in the time of mobile social 
networking (Bergstrom \& Backman, 2013). The breadth of WeChat on its information network, the shortcut of information dissemination, three-dimension product promotion, and interpersonal interaction; all have their own unique characteristics (Zhang, 2015). WeChat has not only allowed the micro e-marketers to interact with the customers, but also allowing the customers to interact with other customers. It is also used to convince customers that the company's products or services are good (Neti, 2011).

WeChat is China's equivalent of WhatsApp, Facebook, and PayPal, all combined into one app (Kontsevaia \& Berger, 2016). It is widely known as one of the world's most innovative and versatile app, as well as China's "App For Everything", with numerous unique functions and platforms ranging from 'payment' to 'social media' to 'services' to 'shopping' and more, that are equivalent to multiple Google Play or App Store's apps, but merged into one (Chao, 2017). WeChat groups share the contents with their friends as well as the contents that users see with their circle of friends (Tang, 2014).

Social media are computer-mediated technologies that facilitate the creation and sharing of information, ideas and interests via virtual communities and networks. WeChat, an online community that targets to provide a space for people to communicate, has now become a well-liked channel for brand marketing (Hassan, 2014). This social networking platform does not only provide users with the option of expanding personal network, it also provides a platform for the business people to interact with potential customers (Blackman, 2009).

Hence, social media are affecting the marketing phenomenon. Currently, there are many different industries who are advertising their products and services via social media whereby big businesses can do better and small business can become better known. Social media have become one of the most favoured marketing strategies used by the business people around the world (Hird, 2013). Social network marketing is a marketing involving online communities. The communities in the social networking sites are large and the gathered users often share similar interests (Jadhav, Kamble \& Patil, n.d.). Unlike the traditional marketing strategy, social network marketing requires marketers to be more attentive to customers to build a better image and relationship with customers (Erdogmus \& Cicek, 2012). Many international companies acknowledge that social network marketing is a potential marketing platform (Neti, 2011). 


\section{Findings and Discussions}

Table 1 shows the demographic profile of 30 respondents who are the micro emarketers with distinct profile.

Table 1: Percentage Distribution

\begin{tabular}{llrl}
\hline Profile Factors & Particulars & $\mathrm{f}$ & $\%$ \\
\hline Gender & Male & 10 & 33.33 \\
\multirow{2}{*}{ Residence } & Female & 20 & 66.67 \\
& East Malaysia & 15 & 50.00 \\
Age & West Malaysia & 15 & 50.00 \\
& 18-21 years & 5 & 16.66 \\
& 22-35 years & 19 & 63.33 \\
Duration of Being Micro & 36-40 years & 6 & 20.00 \\
e-Marketer & Less than 1 year & 4 & 13.33 \\
& 1-2 years & 11 & 36.66 \\
& 3-5 years & 7 & 23.33 \\
Micro e-Marketer Status & 6 years and above & 8 & 26.66 \\
& Full Time & 10 & 33.33 \\
& Part Time & 20 & 66.67 \\
\hline
\end{tabular}

Table 2 presents a list of behavioral strategies and time strategies using content analysis based on the empirical results from interviews and observations.

Table 2: Behavioral Strategies and Time Strategies

\begin{tabular}{ll}
\hline Behavioral Strategies & Time Strategies \\
\hline 1. WeChat Followers & 1. Day Time \\
2. WeChat Self-Branding & 2. Night Time \\
3. WeChat Moments & \\
4. WeChat Groups & \\
\hline
\end{tabular}

\section{Behavioral Strategies}

WeChat Followers Strategy. Everyone can be a micro e-marketer as long as they have a smartphone with Internet connectivity to stay online where social relationships can be established. Through sharing and exchanging information, one is like an online celebrity in WeChat to attract followers. This will indirectly lead to an open possibility to close a sales transaction.

Stay active in WeChat Moments and groups by sharing your life events. Keep in touch with friends in WeChat circle by commenting the posts in Moments. 
Interactions and friend recommendations are essential to create your own profile to illustrate how many people you helped as well as your strengths and capabilities (Interviewee 07).

I don't post about my products all the time! I post about my activities, my business partners and my positive thoughts to attract people. (Interviewee 14).

I share about my daily life happening as if I am a celebrity. I have my followers who love to see my posts. I post about my consumptions of my products and their effectiveness shown obviously on my body. The effects on me speak for me rather than I speak (Interviewee 29).

One of the strategies used by micro e-marketers is to stay active by letting more people know and follow them. Akin to a celebrity, they gain reputation in their endeavour to be whom they desire to appear. An extremely successful example is a campaign by Uniqlo, the Japanese clothing company. As part of their "Style Your Life" campaign, they asked customers to take pictures of the clothes they tried on in-store and post them online, subscribing to the company in the process. During the campaign, they increased their WeChat followers from 400,000 to 1 million. Sales of key clothing items increased by 30 percent (Doland, 2015). That is clearly a highly positive result on using WeChat's advertising platform. With minimal effort, WeChat leads to great success for that business.

You need to create a group of people who get influenced by you and who are willing to pay for your services or products. As long as you have followers, you win! They admire you, they like you, they follow! You need to be able to offer or show your values and skills to attract and maintain your customers, rather than focusing on hard sales (Interviewee 01).

I am a part-time micro e-marketer. At the same time, I am also buying from other trustable micro e-marketers. I will follow the Moments of active micro emarketers that I admire. I look at how they market themselves (Interviewee 13).

Customers are willing to pay for your products or services just because they want to follow you! They place their trust on you! They are willing to try the products that you are consuming (Interviewee 28).

It draws to our attention that it is not about how to sell the products but how the micro e-marketers portray themselves to be an influencer so that people develop trust and are willing to follow. Once micro e-marketers have established their followers, it eases the process of doing sales. To win the followers' heart, it basically depends on the relationships built; making friends, sharing values and offering help while indirectly promoting and selling the products or services that they have to offer. Micro e-marketers portray good personalities and professionalism. Interactions with followers are not to be neglected. As a micro e-marketer, there is a need to understand the followers' needs and wants or their preferences and interests to create WeChat Moments posts. Pressing on hard sales on the products by posting about them all the time is not advisable. Instead, they post something that has values which people prefer to read, for example, tips on 
how to solve a particular problem, humorous or useful information, or about themselves. Successful transactions are done through trust.

WeChat Self-Branding Strategy. Usually branding efforts require extensive financial support for promotion to create brand awareness and later brand loyalty. Social media, with its ideological and technological structure, gives the opportunity to the people to promote themselves as brands in a relatively cheap and efficient manner (Karaduman, 2016). Self-branding is not merely limited to the physical appearance and personal knowledge; it leads to a uniquely distinguishable and memorable impression which includes personal beliefs, values and characteristics.

Self-branding is vital. It concerns the initial feel or first impression on you (Interviewee 02).

Today, the focus has shifted to self-branding. Why not selling (promoting) yourself rather than selling products? (Interviewee 04)

Customers look for me and ask me because they trust my services and products. They believe I can help them. Impressions count! I am my own brand! Show your values and professionalism to your customers (Interviewee 30).

Self-branding enables the micro e-marketers to know their own styles or personalities. Profiling enables them to have a better understanding about themselves and to adapt their behaviours to others or within a team or a relationship. When the micro e-marketers establish their self-branding well, it is easier for people to remember them. Self-branding covers the name, knowledge, skills, experiences, personalities, traits and influences. It is a tool to build trust among the people.

Customers buy from you because they trust you. Customers have been monitoring your posts for quite some time before they bank in money to you. Think about yourself transferring money to a stranger's bank account who you never meet up! (Interviewee 03)

Using your own profile, real name and photo is vital to generate trust from your customers. WeChat Cover Photo serves as your "showroom" to inform others about you. The common mistake is putting ads excessively in WeChat Moments and not showing the real identity by using cartoon or other pictures as profile picture (Interviewee 15).

My strategy is I create a name that represents me and this name is easy to remember. When people think about this product, they think about me. Collecting customers' testimonials or reviews is important as your potential customers read them to know your credibility (Interviewee 16).

I use my own photo as my profile photo so that people know who I am. Avoid group photo. This is to build trust also because nobody wants to buy from a cat or a tree or a cartoon. You may include a meaningful slogan to describe yourself in WeChat What's Up setting (Interviewee 18).

As many online transactions take place involving strangers, thus, it is very important 
for micro e-marketers to have the values of righteousness, integrity and responsibility. A buyer banks in to a micro e-marketer by viewing their products' pictures and descriptions posted online based on trust. The potential customers read reviews to assess the credibility of the sellers. To gain good impression and to enable people to remember them, a unique name is very crucial. Micro e-marketers should use a good name that is easy to recall. The profile photo should represent the real person. The Cover photo in WeChat serves as a business display showroom to inform about the micro e-marketer. In the What's Up in WeChat setting, the micro e-marketers may add a slogan that is meaningful to describe themselves.

WeChat Moments Strategy. To construct WeChat Moments posts, it involves WeChat ads-descriptions and WeChat ads-design. WeChat Moments is a place like Facebook's Newsfeed page where postings are being shown. WeChat ads-descriptions basically contain the texts for expression on micro e-marketers themselves as well as their products or services that are being offered by them. The ads-descriptions should not be too hard selling.

When I wake up in the morning, I like to post about my positive thinking and share it with my own selfie photos. I like to post about useful and informative details to suggest a solution to a problem (Interviewee 17).

I post about the activities of my team or company. People want to know how well I am developing my career and my happenings. I post about interactive activities to stay connected with my friends in WeChat (Interviewee 26).

The description in the post of WeChat Moments should be in a way that it suggests ways of solving people's problems. For example, how to cure a pro-longed cough, how to improve sensitive skin, et cetera. It provides useful information. A simple guessing game or click to like a post invites more to participate for interaction. Suggested techniques of postings in WeChat Moments are as follow: To portray positive thinking and team spirit; to share experiences; to show the testimonials from the customers; to disseminate the latest media news on the products or its company.

I prefer to post a single picture per time. I think it is more effective to grab others' attention because the picture is presented in a clear and big view manner. Nice photos or good designed pictures attract eyes! Write out of the posts have to be interesting, easy to read and not hard selling (Interviewee 09).

Avoid posting two, four, five, seven or eight pictures in a post in WeChat Moments because it will give an empty gap which does not look so nice in the layout presentation. Take note of picture number 5 if you are posting for a total of nine pictures in a post because it is the center of attraction of your post (Interviewee 12).

WeChat ads-design is the pictures that the micro web marketers use to attract WeChat friends to keep an eye on them. It is a good practice to include own photos so that people can relate better. Use relevant wordings to add onto the emphasis of the ads. The pictures that are posted in Moments should be in the number of 1, 3, 6 and 9 for better presentation layout. The first picture is the most important. If 9 pictures are posted, then the first and fifth pictures are crucial. 
WeChat Groups Marketing Strategy. WeChat Groups Marketing technique is utilised by the micro e-marketers for serving multiple people of up to 500 members in a group. The group creator is the leader of the group. They may create their own group or share a group QR code to invite their friends to a WeChat group. WeChat group marketing is to identify the needs of people or solving the problems. Micro e-marketers may enhance their influencing power by giving "WeChat red-packet" in the group, encouraging interaction in the group by answering questions, providing useful information or help when necessary.

I tend to respond to the questions in group by providing them with the useful information to help them in problem solving. This will attract people to make friend with you. (Interviewee 25).

When I enter a new WeChat group, I introduce myself by giving WeChat "redpacket" to catch the attention of others on me. If you give a high amount, people tend to remember you better (Interviewee 27).

Through WeChat group, micro e-marketers may filter and find the people that are willing to buy from them. When questions are being asked in the group, the answers or solutions being provided in the group also give others in the group an opportunity to know and learn. It saves the time of micro e-marketers to reply the same query one by one personally. To get a person to commit a sale transaction, firstly, it must fulfil his or her needs. Second, he or she must have the purchasing power. Third, he or she can make buying decision independently without asking someone else for approval.

In the WeChat group, I will try to find out their needs and their purchasing power. If he or she needs this product and is able to buy it by making own decision, normally the sale will be completed (Interviewee 11).

I love to be in WeChat group to answer enquires as a whole rather than one-byone because some enquiries are the same. It saves my time. Others in the group may learn new things from my reply too (Interviewee 19).

WeChat groups marketing strategy has not only allowed the micro e-marketers to interact with the customers, it also allows the customer to interact with other customers. Testimonials can be shared by customers to convince other customers on a company's products or services. Potential customers are most likely to buy the products to try when they are convinced that the products are good from reliable testimonials. Word of mouth plays a significant influence on the customers' decision.

In a WeChat group, when the existing customers provide testimonials about products, they speak louder than what the sellers say (Interviewee 21).

I love to see or listen to the sharing given by other customers. Word of mouth gives me a reference too in the process of buying (Interviewee 22).

\section{Time Strategies}

The findings show that after waking up in the morning and after dinner time in the evening are two time strategies or the best time to be active in WeChat Moments. 
As a part time micro e-marketer, I stay active in WeChat when I wake up, during lunch time, after office hours and night time after my dinner around 8 'o clock to 11 o'clock (Interviewee 05).

I am active in WeChat during night time, especially after dinner. I post in my Moments before I sleep and when I wake up in the morning (Interviewee 06).

As a college student and part time micro e-marketer, my active time is during night time till midnight. Many students love to stay online till midnight (Interviewee 08).

I wake up and the first thing I do is to check my WeChat to find out any messages from my customers or potential customers (Interviewee 10).

Table 3 presents the best time to be active to post on WeChat Moments by categorizing them into daytime and night time.

\section{Table 3: The Best Time to Post on WeChat Moments}

\begin{tabular}{ll}
\hline Daytime & Night time \\
\hline - $7: 30$ am to $8: 30 \mathrm{am}$ & $\bullet 8: 30 \mathrm{pm}$ to $9: 30 \mathrm{pm}$ \\
- $12: 30 \mathrm{pm}$ to $1: 30 \mathrm{pm}$ & $\bullet 9: 30 \mathrm{pm}$ to $12: 00 \mathrm{am}$ \\
- 5:30 pm to $6: 30 \mathrm{pm}$ & \\
\hline
\end{tabular}

\section{Conclusion}

WeChat has demonstrated a tremendous growth over the years by replacing the need to send SMS as well as the need for phone numbers, as people share their WeChat IDs rather than phone numbers or e-mail addresses (Kontsevaia \& Berger, 2016). This is where mobile marketing starts to evolve tremendously and becomes the latest acclaimed marketing strategy.

Reflecting back on the olden days, people used to have physical shops, then they have slowly shifted to having online websites. The first thing that many people do when they wake up in the morning is to check their smartphone. As such, where the people are is where the opportunities lay, that is on the smartphone, thus on WeChat. Furthermore, nowadays, transactions can be done simply via WeChat, even payment can be made.

The results of the study indicated that it is important to create trust in the customers, in which the focus is on having more followers, self-branding, enhancing effective ads' design and descriptions, along with maintaining productive groups. Listening to customers' needs and wants while being empathetic and understanding is pivotal. Micro e-marketers provide solutions to satisfy the customers in order to complete a transaction. They start the conversation with understanding customers' interests to initiate a good relation which will lead to obtaining the customers' trust.

The developed strategies are effective to generate more sales and thus bringing significant benefits that lead to increased income for individuals, simultaneously creating job opportunities for society and bringing welfare to the nation. It can be summed up that most people are active on WeChat before working, during lunch time, after office hours, after a long day at work as well as before they sleep. Future 
quantitative research is needed to validate the present study empirically with a larger sample in Malaysia.

\section{Acknowledgement}

The authors thank University College of Technology Sarawak (UCTS) for funding this research via UCTS Research Grant.

\section{References}

Bao, A. (2015). Why Brands Should Care about WeChat Advertising. ShengLi Digital. Bergstrom, T. \& Backman, L. (2013). Marketing and PR in Social Media: How the Utilization of Instagram Builds and Maintains Customer Relationship. Media and Communication.

Blackman, A. S. (2009). An Introduction and Outline on How I Will Use Social Networking to Expand My Business. Social Media Marketing. Retrieved from http://asblackman.magix.net/public/index_htm_files/socialpercent20marketing percent20paper.pdf

Chaffey, D. (2016). Our Guide to the Latest Digital Marketing Tools. Retrieved from https://blog.davechaffey.com/

Chao, E. (2017). How WeChat Became China's App for Everything. Fast Company. Retrieved from https://www.fastcompany.com/3065255/china-wechat-tencentred-envelopes-and-social-money

Doland, A. (2015). How Uniqlo Doubles Its WeChat Followers in China: "Style Your Life" Push Allowed Customers to Share Fun Photos in Campaign that Tapped into China's Obsession with All Things Mobile. Advertising Age.

Erdogmus, I. E. \& Cicek, M. (2012). The Impact of Social Media Marketing on Brand Loyalty. Procedia-social and Behavioural Sciences, Vol. 58, 1353-1360. doi: 10.1016/j.sbspro.2012.09.1119

Frater, P. (2017). Tencent's Half-Year Profits Surge to \$4.8 Billion. Variety. Retrieved from http://variety.com/2017/biz/asia/tencent-half-year-profits-surge$1202529416 /$

Hair, J. F., Bush, R. P. \& Ortinau, D. J. (2006). Marketing Research within a Changing Information Environment (3rd ed.). New York: McGraw-Hill/Irwin.

Hassan, A. (2014). Do Brands Targeting Women Use Insta-marketing Differently: A Content Analysis. Marketing Management Association Spring 2014 Proceedings, 62. Retrieved from http://www.mmaglobal.org/publications/Proceedings/2014MMA-Spring-Conference-Proceedings.pdf\#page $=78$

Hird, C. (2013). Social Media Marketing: A Best Practices Analysis of Selected Destination Magazines. Retrieved from http://digitalcommons.calpoly.edu/rptasp/54/

Jadhav, N. P. \& Kamble, R. S. \& Patil, M. B. (n.d.). Social Media Marketing: The Next Generation of Business Trends. IOSR Journal of Computer Engineering (IOSR$J C E), 45-49$. Retrieved from http://www.iosrjournals.org/iosr-jce/papers/sicetevolume2/21.pdf

Karaduman, I. (2013). The Effect of Social Media on Personal Branding Efforts of Top Level Executives. 9th International Strategic Management Conference, Procedia - Social and Behavioral Sciences 99, 465 - 473.

Kontsevaia, D. B. \& Berger, P. D. (2016). Mobile Marketing in China: Can WeChat Turn 
Their New Advertising Strategy into a Sustainable Advantage? International Journal of Marketing Studies, Vol. 8, No. 4, 37-43.

Neti, S. (2011). Social Media and its Role in Marketing. International Journal of Enterprise Computing and Business Systems, Vol. 1, Issue 2. Retrieved from http://www.ijecbs.com/July2011/13.pdf

Rachel, G., (2018). WeChat Pay just Launched in Malaysia. Retrieved from https://www.businessinsider.com/wechat-pay-malaysia-2018-8/?IR=T

Tang, Min. (2014). Research on WeChat Marketing Strategy of Enterprises Which Is Based on the SICAS Model. International Journal of Business and Social Science, Vol. 5, No. 6(1), 213-217.

Yang, X. M., Li S. S. \& Lee R. P. (2016). Micro-Innovation Strategy: The Case of WeChat. Asian Case Research Journal, Vol. 20, 401-427.

Zhang, P. (2015). Research on Strategy of Model Innovation of WeChat Marketing. Joint International Mechanical, Electronic and Information Technology

Conference. 